\title{
Towards an Information System Making Transparent Teaching Processes and Applying Informing Science to Education
}

\author{
Antonio Cartelli \\ University of Cassino, Cassino (FR,) Italy
}

cartan@unicas.it

\begin{abstract}
The paper first describes the main features of the project for vocational and educational guidance the author recently planned. The main aim of the project was to help students develop self guidance skills and overcome the difficulties they meet at school. The information system used in the project was based on the use of action research and social statistic strategies and calculations for the analysis of individual and population features.

The paper then analyzes two recent events: a) the investigation the author carried out together with some teachers in Italian High Schools (Liceos) on an educational guidance action, and b) the elements of innovation introduced in the Italian School system by a recent Reform Law.

Last, after a re-consideration of the initial project, the features of a new information system, to be used both for assessment and guidance (i.e., it includes an e-portfolio for skills and guidance), and the role that informing science can play in helping teachers, students and families are reported.
\end{abstract}

Keywords: Action Research, Assessment, E-Portfolio, Educational and vocational guidance, Information System, Informing Science.

\section{Introduction}

In a recent study the author reported the points of view of psychology and didactics in educational and vocational guidance and the following remarks were pointed out (Cartelli, 2004): a) psychological research achieved good results in helping subjects in their developmental and educational growth and produced many instruments for the analysis of their affective, relational and cognitive spheres; i.e., tests, surveys, questionnaires and many kinds of interviews, b) didactics, on another hand, developed many teaching strategies, which can be successfully applied all together or separately in everyday class-work on the basis of the data emerging from the systematic observation of students (i.e., the results of many experiences show that a careful planning of teaching can contribute to students' acquisition of a meaningful learning).

In the same work (Cartelli, 2004), pros and cons in the application of theories and methods of

Material published as part of this journal, either on-line or in print, is copyrighted by Informing Science. Permission to make digital or paper copy of part or all of these works for personal or classroom use is granted without fee provided that the copies are not made or distributed for profit or commercial advantage AND that copies 1) bear this notice in full and 2) give the full citation on the first page. It is permissible to abstract these works so long as credit is given. To copy in all other cases or to republish or to post on a server or to redistribute to lists requires specific permission from the publisher at Publisher@InformingScience.org psychology and didactics were analyzed and the results of recent studies on guidance actions were reported.

The main result of those studies was the evidence of elements having good effects in guidance actions for the help they gave to students, families and teachers in overcoming the difficulties 
they met. The list of these elements is reported below:

1. Methods and instruments of didactics and psychology must be jointly used in everyday schoolwork; they both are, in fact, involved in the analysis of students' learning and educational environments. In other words, teaching planning, mostly pertaining to didactics, must include guidance in the teaching-learning process (i.e., special jobs helping students in the development of self-guidance skills have to be planned together with teaching of the disciplines' topics); furthermore, instruments and methods for the analysis of students' evolution and involvement in school life, mostly pertaining to psychology, must be systematically used from teachers to find elements helping students in overcoming their difficulties and giving them the instruments for the planning of suitable guidance interventions.

2. The action research strategies must replace the hypothetical-deductive models often used in psychological and didactical approaches to guidance actions for interpreting phenomena.

3. The monitoring of teaching-learning (i.e., the screening of educational processes and of their actors) has to support the students' evaluation and assessment and the analysis of their relational and affective spheres.

The first point is the natural consequence of the diachronic-continuous evaluation of students' behaviors and processes involved in the guidance action, rather than the synchronous-ending evaluation of the same elements.

The second point strictly depends on the first one because of the features of the action research inquiry method. It is well known, in fact, that action research fully immerses the researcher in the reality he/she is studying and modifications he/she induces in the phenomenon under investigation are an integral part of this research method (Scurati \& Zanniello, 1993). On the other hand, traditional (Susman \& Evered, 1978) and more recent (Baskerville, 1997) descriptions of action research methods and techniques detail a five phases cyclic process, which can be easily identified with the one marking the planning and developing of every guidance action: 1) diagnosing, 2) action planning, 3) action taking, 4) evaluating and 5) specifying learning. And last, it has to be noted that very common consequences of action research strategies are: 1) people involved in the inquiry have a closer and wider message transfer rate while communicating among themselves, 2) researchers pay close attention to ethical considerations in managing their work.

Richard Winter (1996), in the following principles, described action research inquiry steps better than the above two remarks:

- relevant persons, committees and authorities must be consulted before starting any work, and principles guiding this work have to be accepted in advance by all,

- all participants must be allowed to influence the work, and the wishes of those who do not like to participate in the work must be respected,

- the development of the work must remain visible and open to suggestions from others,

- permission must be obtained before making observations or examining documents produced for other purposes,

- description of works and points of view coming form people not directly involved in the work must be negotiated with them before being published,

- the researcher must accept responsibility for maintaining confidentiality.

As regards the third point, it has to be noted that the monitoring of activities and processes in a guidance action can be achieved with the help of ICT (Information and Communication Technologies) and especially with the joint contribution of the following two elements: 1) the use of 
data storage and retrieving strategies (i.e., data mining methods) and 2) the adoption of Web technologies.

When working with a large population (more than 20-30 individuals) the simple storage and retrieving of data for the analysis of social phenomena and, especially, for guidance actions cannot help researchers in finding the right elements needing the planning of recovering interventions. The application of social statistic methods to data stored in the information system can lead, on the contrary, to the discovery of new features in the population under observation (i.e., usual statistical parameters such as mean value, range, standard deviation, asymmetry, kurtosis etc. can trace a profile of the population different from the ones of the subjects belonging to the universe to be analyzed). Furthermore, the comparison of individual's features with those of the whole population helps all stakeholders involved in the study of the phenomenon to find anomalies and unusual behaviors requiring further investigations and planning of new researches or interventions.

From the above remarks emerged the hypothesis of an information system with the following features: a) different accesses for the various users of the system, b) guaranteed security and privacy for each user, c) easy input of the information concerning the students' aspects and the environmental data (i.e., by means of Web forms which could be accessed from everywhere: school, home etc.) d) easy access, depending on the assigned permissions, to statistical information like historical series of the individual data or indexes describing groups of students or the whole population under observation, e) easy drawing of the individual and global variables' distributions and finding of the subjects with anomalous or extreme values in the distribution, f) strong presence of communication instruments like e-mail services, electronic blackboards, chat etc.

The action-guidance project (This was the name for the project based on the above information system.), had to revert the usual, well-established and pre-defined strategies, until now adopted in the management of educational and vocational guidance, to let it become an event-driven phenomenon. In this way students' expectations and skills and the relations they established among themselves became the phenomena to observe and translate into indices describing the environment within which the guidance action had to be planned and analyzed from families, teachers and guidance staff. The continuous feedback coming from those indices helped all stakeholders in managing every kind of situation and preventing students from drop out and failures.

\section{Data from Research and Reality and their Influence on the Action-Guidance Project}

The planning of the information system the author hypothesized for the carrying out of the actionguidance project required finding suitable indices for students' description and for the analysis of their evolution over time (first of all the development of self-guidance skills).

During school year 2003-2004 a guidance action was carried out in cooperation with teachers of Italian High Schools (Liceos) with the main target of identifying some of the above elements and finding the strategies better describing students' self-guidance features.

In 2004, on the other hand, new elements intervened in modifying the reference context and the planning of the project so that a reconsideration of its structure became evident. It started, in fact, the reform of the Italian school system, which introduced many innovations in teaching organization and management of Italian School.

In the paragraphs below these elements are analyzed in a greater detail for the consequence they have in what follows. 


\section{The Guidance Action Experience in the High School}

The guidance action the author planned in cooperation with teachers of the High School (Liceos) had special features; it was devoted, in fact, to the analysis of informal education influence on students' performances and success. This choice was mostly due to the results of some studies which evidenced the difficulties psychology and didactics met while explaining students' results and especially: a) psychological follow-up analyses, carried out on different sets of students, which showed very little or no correlation between the scores the students got in the High School and their success in further academic studies (Boncori \& Boncori, 2002), b) the didactical measure and evaluation of school teaching by means of cognitive investigations carried out on national and international bases (IEA, IEA-SISS, IEA-SAL), which showed the inadequacy of the school system in the achievement of predefined cognitive targets (at least in Italy) (Domenici, 2001), and c) the lack of adequate scientific literature on the influence of informal education elements on students' school performances and success.

The guidance action was made with first year students of the High Schools (67 subjects). The teachers involved in the experience were employed in during school year 2003-2004. The main aims of the investigation were: a) to determine the possible influence of environmental indices on students' performances and satisfaction during the first school year, and b) to find, if possible, the least time interval for the planning of recovering interventions devoted to overcoming the difficulties the students met at school. Three main phases were identified: the welcome at the entrance, the self-knowledge (students' auto-analysis at half of the school year) and the transition (at the end of the school year). The investigation of the above phases was made with annotation cards, report cards, interviews, surveys and questionnaires, mostly adopting open answers (the answers of the students were then collected and organized as reported in the tables below).

As regards the first phase (welcome at the entrance) the following elements were analyzed: the places the students came from (with respect to the school they attended), their social environment, the reasons inducing them to attend that school and the availability of instruments for cultural enrichment outside the school (i.e. TV use and the programs they liked most, newspapers and magazines read, PC availability and use etc.). Main results of this first inquiry are reported in Table 1 .

Table 1: Percentage of students' distribution in the first phase survey

\begin{tabular}{|c|c|c|c|}
\hline Towns the students came from & the same $(45 \%)$ & \multicolumn{2}{|c|}{ others $(55 \%)$} \\
\hline Students' social standing & low $(45 \%)$ & medium $(50 \%)$ & high (5\%) \\
\hline Time spent watching TV & $<2 \mathrm{~h}(10 \%)$ & $=2 \mathrm{~h}(45 \%)$ & $>2 \mathrm{~h}(45 \%)$ \\
\hline Influence on school choice & autonomous (67\%) & $\begin{array}{c}\text { parents' suggest. } \\
(21 \%)\end{array}$ & $\begin{array}{l}\text { teachers' suggest. } \\
\qquad(12 \%)\end{array}$ \\
\hline Newspapers and magazines reading & sport / comics $(62 \%)$ & \multicolumn{2}{|c|}{ newspapers (18\%) } \\
\hline PCs' access & at home $(73 \%)$ & \multicolumn{2}{|c|}{ with relations / friends $(22 \%)$} \\
\hline PCs' use & $\begin{array}{c}\text { browsing / searching } \\
(68 \%)\end{array}$ & $\begin{array}{c}\text { playing / chatting } \\
(64 \%)\end{array}$ & $\begin{array}{c}\text { downloading files } \\
(32 \%)\end{array}$ \\
\hline
\end{tabular}

More exactly the table's rows state: a) students needed from a few minutes to half an hour or a little more to reach the school (only $45 \%$ of them lived in the school town), b) students' families had very different social standings, also the largest group of them (about 50\%) were children of professionals and teachers, c) students spent two hours a day or more watching TV $(45 \%$ among them two hours and $45 \%$ more than two hours), d) many students (67\%) chose that school be- 
cause they thought it was the more suitable one and only a part of them accepted parents' $(21 \%)$ or teachers' $(12 \%)$ suggestions, e) many students read sport's or comic's magazines $(62 \%)$ and only a few of them read newspapers $(18 \%)$, f) many students could access a PC at home $(73 \%)$ or with the help of friends and relations (22\%) and g) used it for playing and chatting $(64 \%)$, for browsing sites (32\%), for searching information (36\%) or for downloading files of different type (mostly music ones) (32\%).

Halfway through the school year the following elements were analyzed: the level of engagement the students perceived, the interest for disciplines and topics they studied, the presence of difficulties, how they overcame them and the level of satisfaction they experienced as a consequence of the school choice. Main results of this inquiry are reported in Table 2.

\begin{tabular}{|c|c|c|c|c|c|}
\hline \multicolumn{6}{|c|}{ Table 2: Percentage of students' distribution in the second phase survey } \\
\hline School engagement & very high $(69 \%)$ & \multicolumn{4}{|c|}{ enough binding $(31 \%)$} \\
\hline $\begin{array}{l}\text { Level of interest for topics and disci- } \\
\text { plines in the curriculum }\end{array}$ & very much $(42 \%)$ & \multicolumn{2}{|c|}{ enough (54\%) } & \multicolumn{2}{|c|}{ low $(4 \%)$} \\
\hline \multirow{2}{*}{$\begin{array}{l}\text { Presence of problems in the study } \\
\text { and types of problems }\end{array}$} & \multirow[b]{2}{*}{ no one $(24 \%)$} & \multicolumn{4}{|c|}{ different kinds of problems $(76 \%)$} \\
\hline & & $\begin{array}{l}\text { topics } \\
(63 \%)\end{array}$ & & & $\begin{array}{l}\text { teachers } \\
(4 \%)\end{array}$ \\
\hline Overcoming of problems & $\begin{array}{l}\text { yes - greater engage- } \\
\text { ment }(43 \%)\end{array}$ & \multicolumn{2}{|c|}{ no $-(24 \%)$} & \multicolumn{2}{|c|}{$\begin{array}{c}\text { do not answer } \\
(33 \%)\end{array}$} \\
\hline Global satisfaction & yes $(66 \%)$ & \multicolumn{2}{|c|}{$\begin{array}{c}\text { no final answer } \\
(24 \%)\end{array}$} & \multicolumn{2}{|c|}{ no $(10 \%)$} \\
\hline
\end{tabular}

As stated in the rows of the table: a) many students (69\%) stated they were highly engaged and the others (31\%) they were only enough, b) $42 \%$ of the students said the disciplines they studied were very interesting but many others (54\%) said they were only enough interesting or (4\%) a little or not at all interesting, c) from the analysis of the difficulties the students met emerged that only a part of them had no problem (24\%), many students, on the contrary, had problems with the topics to be studied $(63 \%)$, with their colleagues $(9 \%)$ or with the teachers $(4 \%), d)$ it has to be noted that $43 \%$ of the students overcame the problems they met with a greater engagement (they did not state if they needed help or not), $24 \%$ of them did not overcame their problems or did not answer to the question (33\%), e) at last $66 \%$ of the students were satisfied of the school they chose but $10 \%$ were not and $24 \%$ could not give a definite answer to that question.

On the basis of the above data many actions involving students and their families were planned and carried out for helping both in overcoming the difficulties they experienced in the first part of the school year. Furthermore the comparison of the data obtained in the second survey with the ones from the first inquiry, and especially the analysis of correspondences among themselves, showed there was little or no correlation among environmental parameters and new variables: i.e., students who experienced difficulties or dissatisfaction were distributed among all environmental parameters reported in Table 1 and just the same was true for those who experienced no difficulties or were satisfied of their performances. There has been only a positive (but very little) correspondence between the social status variable and the overcoming of the school difficulties (i.e. students living in medium/high social standing families more easily overcame their problems).

At the end of the school year a balance of the students' experience was made and the following elements were analyzed: the number of hours they spent everyday for studying, the level of their performances, the relationships they established with colleagues and teachers and their general satisfaction. Table 3 summarizes the results of the survey. 


\begin{tabular}{|l|c|c|c|}
\hline \multicolumn{4}{|c|}{ Table 3: Percentage of students' distribution in the third phase survey } \\
\hline Medium N. of daily hours studying & $<2(10 \%)$ & $2-3(33 \%)$ & $>3(57 \%)$ \\
\hline Satisfaction for school performances & $\begin{array}{c}\text { At all } 24 \% \text { (disci- } \\
\text { plines' problems) }\end{array}$ & partially (28\%) & really (48\%) \\
\hline Satisfaction for staying at school & $\begin{array}{c}\text { Problems with teach- } \\
\text { ers (39\%) }\end{array}$ & $\begin{array}{c}\text { Well - with } \\
\text { friends (67\%) }\end{array}$ & $\begin{array}{c}\text { Well - with } \\
\text { teachers (54\%) }\end{array}$ \\
\hline Satisfaction for school year trend & No good (11\%) & \multicolumn{2}{|c|}{ Good (89\%) } \\
\hline
\end{tabular}

In other words: a) more than $57 \%$ of the young people studied more than three hours every day (while sacrificing other activities) and 33\% of them from two to three hours, b) only $48 \%$ of the students was really satisfied with his/her performances, $28 \%$ was only enough satisfied and the others were not satisfied at all and had more or less problems in many disciplines, c) most of the students were satisfied at school with their friends (67\%) and teachers (54\%) and had problems only with some teachers (39\%), d) at least $89 \%$ of the students stated they were satisfied with the school they were attending and would have confirmed their choice, $11 \%$ of them on the contrary were not satisfied and had doubts on their future success. The main result of this inquiry is the recovery of only a part of the students who evidenced problems at the second inquiry; notwithstanding the activities held in the second half of the school year (i.e. a closer connection schoolfamilies and some make up courses for students with inadequate scores), it has to be noted that $11 \%$ of students still had problems and had serious doubts on their performances in next years. Furthermore, this survey confirmed the results of the second one: no evidence or definitive correspondence was found among the environmental parameters (i.e. informal education influence) and the students' success at school.

Together with the data reported above two main results can be stated for the action guidance experience: a) the continuous monitoring of educational processes really can help teachers, students and families in overcoming the problems and troubles they met and in reducing the number of students experiencing the same problems at the end of the school year (i.e., data mining strategies applied to school and environmental data can be very useful in helping the actor of teaching learning processes), b) the monitoring by itself cannot be correlated to the development of better self assessment and self guidance skills in the students (no reason has been found for a change of students' features due to the same monitoring).

Furthermore the analysis of students behaviors that Varisco (2002) made on communities of learners, and the results of sample interviews the author and the teachers involved in the guidance action made on some students at the end of the experience described above, resulted in the hypothesis that a greater involvement of students in the analysis, description and reflection of their school experiences (i.e., meta-cognition on their school experience) could help them in developing the self guidance skills not induced by traditional school activities.

\section{The Reform of the Italian School System}

During last 70 years the Italian Parliament and the Ministry of Education intervened in different ways to modify programs and teaching processes in the various school levels, but never the structure of the Italian school system was modified so deeply as it was in last two years.

Before last changes the Italian school system was based on three school levels: primary school (711 years old students), secondary school of first degree (Junior High School with students from 12 to 14 years old) and secondary school of second degree (High School with 15-17 or 15-19 
years old students). Italian High School was split into three main components: the vocational one (three years long), the technical one and Liceos (both ones five years long).

Law n. 53, published in 2003, reformed the Italian school system by introducing only two school cycles: the first one (including both Primary and Junior High Schools - 8 years long) and the second one (where only vocational schools -4 years long, and Liceos -5 years long, can be found). (See Note 1 for how to access these documents.) Law 53/2003 found its first application in 2004 with the decree n. 59, concerning the first school cycle, and stated that the new school system had to start with the school year 2004-2005 (involving the first year of the primary school and the first year of the Junior High School).

A detailed discussion of the Reform Law and the changes it introduced in the structure and the management of school organization is beyond the object of this paper, also, because the reform is still in progress (some changes in the first cycle have been recently applied and the second cycle has not yet started) and it could be modified in one or more of its parts. Nonetheless it is important for what follows to analyze some of its elements:

- it is based on the "Educational, cultural and vocational profile" of the student, i.e. the set of things he/she must know (discipline and inter-discipline knowledge) and be able to do (operating and vocational skills) at the end of his/her first school cycle to be the man/woman and the citizen commonly meant in the society (the features of the profile are clearly defined and listed in the enclosure $d$ of decree n. 59),

- the schools must personalize the students' curricula (called study programs), coherently with their educational profiles, by organizing and coordinating teaching work as it emerges from national suggestions, by the acceptance of cultural and educational proposals coming from families and by integrating school activities with the ones made available from local institutions (a part of school time must be devoted to these activities),

- the organization of educational and teaching activities is referred to teachers. Among them a teacher having special training (called tutor-master) is charged of the following tasks: a) be responsible for the continuous contact with families and environment, $b$ ) have guidance functions for the choice of the activities to be included in the students' personalized study program, c) coordinate educational and didactic activities, d) mind the connections with students' families, e) mind the documentation of the student's instruction route, with the help of other teachers,

- the students' career is documented in the "portfolio of individual skills". It collects notes coming from teachers, parents and (eventually) the same student, which are selected among: a) works describing the best skills of the student (made individually or in a group), b) significant school tests, c) remarks on student's learning coming from teachers and families, d) remarks on special works, e) examination papers the student, the family or the school propose for the inclusion in the portfolio (reporting meaningful examples of the student's skill and wish), f) synthetics remarks coming from systematic observations, teachers-family meetings, speech with the student and questionnaires or surveys concerning the student's bents and interests. The portfolio is made of two parts: the former one is devoted to the student's evaluation and assessment, the latter one is devoted to guidance; portfolio must be compiled and brought up to date from the tutor-master teacher.

The points reported above concern only some aspects of the new Italian School system and the whole documentation concerning the reform can be found in the Web site of the Italian Ministry of Education and in other sites of Italian public institutions involved in educational research. (See Note 2.) For what follows it is important to remember here the contributions Bertagna (2003), Comoglio (2003) and Vaj (2003) gave to the description of the reform and to the portfolio fea- 
tures and use. In their documents, in fact, they draw many features of the portfolio and report many examples of its applications.

\section{Implications for the Action-Guidance Project}

Two kinds of remarks can be stated from the elements in the above paragraphs.

First of all, no significant correspondence between students' environmental parameters (i.e., indices the author hypothesized to influence students' informal learning) and their school success could be stated, at least in the investigated type of school and school year (notwithstanding it was a special one, the first High School year). Furthermore a greater involvement of students, families and teachers in the analysis, evaluation and assessment of school experiences seemed relevant in determining the development of better self assessment and self guidance skills in students. As a consequence the original idea of an information system using data mining strategies for the analysis of individuals and population features (as proposed with the action-guidance project) was still actual.

Secondly, it has to be noted that Law n. 53 and its application decrees are producing a revolution in the Italian school system for their pedagogical implications and for the influence they have on teachers' work organization. A general positive judgment has been given from many pedagogists on the reform in its entirety, mostly because of its consideration of students' age and evolution during the first cycle of instruction and the consequent overcoming of ancient and pre-defined learning stages. Furthermore the personalization of students' curricula and the use of the portfolio are introducing new elements in teaching planning and carrying out and in evaluation and assessment procedures. As a consequence the need for the management of these features cannot be neglected in a project aiming at involving all actors in the Italian school. Data coming from the evolution of teaching work and from students' evaluation and assessment can be analyzed, synthesized and represented by the information system to let people constantly observe and monitor phenomena and intervene on them.

As regards teachers (who firstly are involved in the application of the reform) two main remarks deserve attention: a) many resistances are emerging from the distinction of roles and functions proposed from the reform for the master-tutor with respect to other teachers, $b$ ) personalization of curricula and portfolios (and especially official documents teachers must compile) are considered the reason for a great amount of new work, the main consequence of which can be the bureaucratization of teaching. As an example it has to be remembered what happened approximately ten years ago when a complex report card analytically analyzing students' features (very similar to a case history) was introduced in the Italian primary school and Junior High School. Teachers were forced to spend a lot of time (outside school) in compiling it and in using a relevant part of their school time to collect and describe student's features, more than teaching. Many protests were continuously made against that report card so that two or three years later the Ministry of Education abandoned it.

Furthermore many studies on portfolios and e-portfolios showed a different use of this alternative assessment instrument with respect to what Italian reform proposed for it. It has to be noted, in fact, that in many Anglo-Saxon contexts, portfolios directly involve students, and people more in general, in their compilation and updating, so helping them in developing self assessment skills. Italian reform (at least as it can be deduced from the documents explaining it), on the contrary, commits the management of the portfolio to the master-tutor teacher: he/she must collect suggestions from colleagues, students and families and must compile the student's dossier, but he/she remains the only responsible for the management of all data and information in the portfolio.

Remarks reported above are further hints for the development of a new information system with the following features: a) make easier for teachers the work of collecting and analyzing data com- 
ing from students, b) overcome the differences in the perspectives of portfolios' use by the adoption of suitable strategies in the collection of personal data.

\section{Integration of the E-Portfolio in the Action-Guidance Information System}

If the introduction of an e-portfolio in the action-guidance information system seems the natural consequence of what has been reported in the above paragraph, the only problem arises from the difficulty of building an information systems adequately answering to all expectations. Love and Cooper (2003) showed in fact that the use of online environments for the implementation of portfolios rarely realize the benefits they could produce. They suggest that this is due, in general, to inadequate, over-simplistic or unsophisticated approaches to the design of these on-line systems. They identify four weaknesses in most typical approaches to the design of online portfolio systems. The first one happens when the design brief omits most of the key educational and administrative issues, and, instead, focuses mostly on identifying technical means. The second weakness is where the 'online portfolio' consists only of a single essay, project report or term paper presented as a web-based electronic facsimile of a conventional document (i.e., single pieces of work cannot be considered portfolios nor do they automatically gain the benefits of portfolio-based systems as a result of the renaming). The third weakness is where designs for online portfolio assessment systems are based on an over-narrow view of value distribution that does not take all stakeholders into account; it usually happens when teaching and learning aspects are overemphasized and the value that can be added to other institutional and educational processes are neglected. The fourth weakness occurs when the designing of online portfolio assessment systems is not well integrated with overall course design processes. Many of the benefits associated with online portfolio assessment systems come from improvements in efficiencies that reduce the resource costs associated with the provision of education adopted.

In Love and Cooper's opinion an alternative approach to designing online portfolio assessment systems must consider:

- the identification of the nature and characteristics of the educational and institutional contexts for which the online portfolio assessment systems is designed (and evaluated)

- the identification of potential benefits and increase in value for all stakeholders

- the development of heuristics for prioritizing value distributions

- the development of an online system through the use of best practices in course design, i.e.

0 the fulfillment of the requirements of the course criteria

$\circ$ the integration of the designing of the online portfolio system with the broader course design processes

The above remarks guided the introduction of new elements in the original project and induced relevant changes in the information system planning. Teachers involved in the guidance action carried out in school year 2003-2004 and colleagues from primary school were invited to work in a team for the analysis and discussion of the features of the e-portfolio of skills and guidance. Parents of the students attending the schools involved in the project (some among them were teachers in the same or other schools) were also invited to give their contribution in the information system planning. From the discussions emerged the following guidelines for the carrying out of the information system in its entirety and especially the e-portfolio within it:

1. it has to comply with Law 53/2003 and its application decrees,

2. it must contain the personalized study program for each student, 
3. it must synthetically describe the students' participation in school activities and their presence at school (i.e. student's absence, later entrance and earlier exit from the school),

4. in the e-portfolio the students and their families must find teachers' evaluations, assessments and observations on school planned activities (concerning students' cognitive, sociorelational and affective spheres); furthermore the information system must contain the elements letting teachers, students and families look and control the evolution of the teachinglearning activity,

5. students and their families must play a relevant role in the compilation of the e-portfolio section concerning special or extra-school experiences; i.e. the description of such experiences must be as easier as possible and must be helped by the presence of a sequence of steps preorganizing its compilation. At last a special subsection concerning the self-assessment of the experience (in the first cycle school this section can be compiled from families and students all together, in second cycle schools it can be compiled from the students) must be present,

6. it must describe the environmental parameters probably influencing students' performances and must help all stakeholders in controlling their evolution with the time,

7. not necessarily it must contain digitized documents, photos, animations or films describing students' experiences and in the first phase of its carrying out these elements are not allowed.

\section{Structure of the Information System and the e-portfolio}

The structure and the functions of the information system for the management of the environmental data and the on line portfolio to be adopted in the school lay on the following elements: a) the data base structure, b) the users who can access the data base and the operations they can do, c) the query system and d) the data flow. To store the data a relational data base management system was adopted (i.e. PostgreSQL); the access to the data was guaranteed from a dynamic Web site (based on the Web server Apache and on the interfacing language PHP). In what follows the above elements are described in a greater detail and Figure 1 summarizes the information system structure and data flow:

a. the data base is made of the following tables: 1) student, containing students' main data; 2) family, hosting the data of students' families and environmental parameters (it must be updated once a year), 3) school, identifying the school and its features (i.e. the formative offering plan or the set of all planned school activities), 4) teacher, describing teachers' main features (their ID and password too) and the classes they are assigned to, 5) stuscho, linking every student to his/her class and to the corresponding teachers, it also identifies the tutormaster teacher for each student, 6) stupres, collecting students' presence at school, their later entry or earlier exit from the school, 7) learnun, describing learning units as suggested from the Ministry of Education, with a special attention to cognitive (Bloom, 1956), sense-motor (Mialaret 1999), and affective (Krathwohl et al., 1964) taxonomies, 8) persunit, collecting for each student learning units belonging to his/her personal study program (it is not necessarily unique and all students in a class can have the same "study program"), 9) assess, containing the students' assessments as they emerge from the documents used to measure the acquisition of cognitive, sense-motor and affective objectives in the learning units contained in personal study programs (a seven values scale, from null to optimum, for each item in the taxonomy is used), 10) extra, is the table for the description of special or extra-school experiences students and/or their families will like to include in the portfolio; it is made of four sections: the first one identifies and describes the experience, the second one evidences its main target and the student's self assessment of the experience, the third one contains remarks and comments of other students involved in that experience (if there are), the fourth one reports the judgment of 
the manager/s of the organization accepting the student for the experience (if there are), 11) commun, letting users communicate by special forums and electronic blackboards;

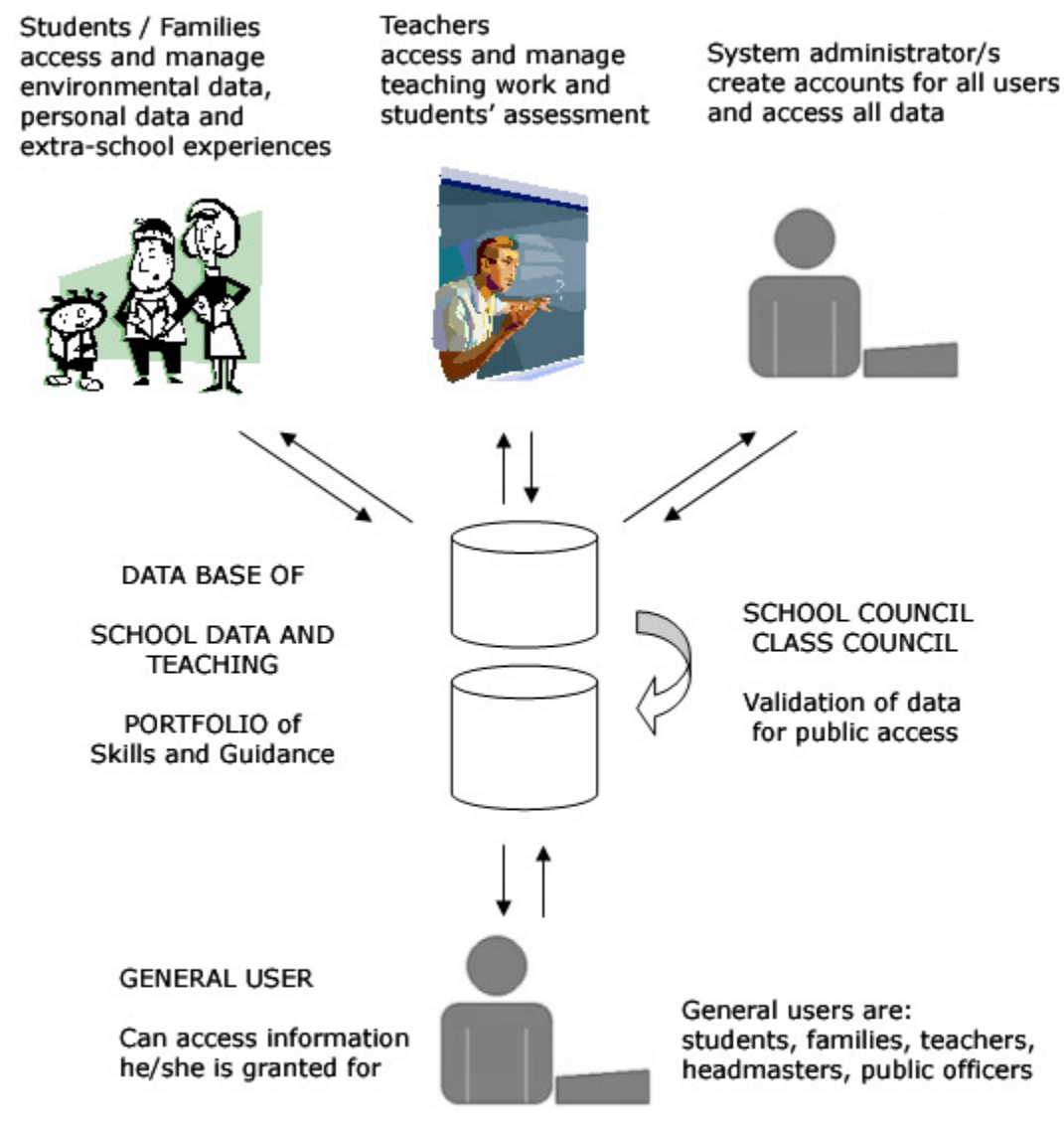

\section{Fig. 1 - Information System draft and data flow}

b. users accessing the data base have different rights and powers: 1) the user with the least rights on the data is the one who can only query the system to obtain general information on schools involved in the project and on the evolution of their educational activities (a general user can only access the school POF - Piano dell'offerta formativa = Formative Offering Plan and its evolution), 2) at an upper level are the students and their families, who can access special Web areas (by means of their ID and password) with a menu of the allowed operations, i.e. they can input and modify their general data, can input and modify all information concerning special or extra-school experiences to be included in the portfolio, can look at the evolution of teaching work, at the carrying out of the student's personal study program, at the student's presence at school and at the student's assessment, 3) just in the same way teachers can manage all data concerning teaching planning and evolution (with the assignment of learning units and personal study programs to the students), students' assessment (it has to be noted that these data become integral part of the portfolio and can be accessed from students and families only after validation from the tutor-master teacher; i.e., after the definitive approval by the class council), 4) tutor-master, among all teachers, has a special role because validates students' assessment and all data to be included in the portfolio (after the class council), 5) at the top of the access pyramid is the system administrator who can do all the operations allowed to teachers and tutor-masters and can access the verified data to modify or to delete them; 
c. as already remarked not all information in the data base can be accessed from everyone, i.e. personal information can be seen only from people who is authorized to access them. Personal data like students social status and environmental variables, students' study programs, evaluations and assessments can be accessed only on a statistical basis from educational researchers. General school information, like the formative offering plan (POF) and its specification in the different classes of the school, are available to everyone.

d. the first step in system management is obviously the input of data concerning students, families, teachers, school and learning units; soon after teachers can record data concerning their everyday work and especially students' personal study programs, presences and assessments. The tutor-master (after approval of the class council) will validate the data and they will be accessed from allowed people.

\section{Conclusion}

Until now only three schools of different level (i.e., one class for each of them) are implementing their data in the system, and it is too early to draw any conclusion about the use of the information system and the e-portfolio, mostly because its use is just at a first stage and fundamental data have not yet been stored into the system.

Nonetheless, it has to be noted that the involvement of so many people during the planning phase of the system has already produced positive effects because of a general agreement on its features, its use, and the target to be reached.

A first consequence of the acceptance of the information system is, in the author's opinion, the attempt of using traditional and well settled instruments of evaluation together with new alternative instruments like e-portfolios and, what's more, the transformation of the teaching-learning process. All actors involved in this process, that is students, families and teachers, have in fact accepted the idea of the "transparence of the didactic process", which is underlying the use of the information system described above.

A special role has been played in this context from Informing Science as the discipline that "provides its clientele information in a form, format and schedule that maximizes its effectiveness" (Cohen, 1999). The clients are now of two kinds: on one hand there are the students, their families, the teachers and the institutions, i.e. the actors of every educational process; on another hand there are scholars and researchers of the disciplines usually involved in the analysis of the teaching-learning process: Technologies of education, Didactics, Curriculum and Organization Theories, Psychology, Sociology and Philosophy. All clients together can work to help students in obtaining better results and obtaining new elements for describing knowledge construction and development in mankind.

\section{Notes}

1. All documents concerning the School Reform can be retrieved from the Web site of the Italian Ministry of Education: http://www.istruzione.it/riforma/index.shtml. On the same site the single norms can be found (retrieved December 2, 2004, from the sites below)

Law n. 53/2003: http://www.istruzione.it/normativa/2004/legge53.shtml Decree n. 59/2004: http://www.istruzione.it/normativa/2004/dec190204.shtml

2. Many documents on the Italian reform, written by scholars and scientists, are available at the INDIRE Web site (National Institute for Teaching and Educational Research) at the following address: http://www.bdp.it/inriforma/pdf/ 


\section{References}

Baskerville, R. (1997). Distinguishing action research from participative Case studies. Journal of Systems and Information Technology, 1 (1), 25-45.

Bertagna, G. (2003). La progettazione della riforma: Lessico pedagogico di riferimento. Retrieved December 2, 2004, from http://www.bdp.it/inriforma/pdf/Progettazione_riforma_lessico_pedagogico_rifer.pdf

Bloom, B. (1956). Taxonomy of educational objectives. Handbook I: Cognitive domain. New York: Longmans \& Green.

Cartelli, A. (2004). Action-guidance: An action research project for the application of informing science in educational and vocational guidance. Journal of Issues in Informing Science and Information Technology, 1, 773-792.

Cohen, E. (1999). Reconceptualizing information systems as a field of the transdiscipline informing science: From ugly duckling to swan. Journal of Computing and Information Technology, 7 (3), 213-219. Retrieved December 2, 2004 from http://informingscience.org/WhatIS.htm

Comoglio, M. (2003). Insegnare e valutare con il portfolio. Retrieved December 2, 2004, from http://www.bdp.it/inriforma/pdf/portfolioarticolo_comoglio.pdf

Domenici, G. (2001). Manuale dell'orientamento e della didattica modulare. Bari: Laterza.

Krathwohl, D. R. (1970). Taxonomie des objectives pedagogiques. Tome II: Domain affectif. Montréal: Education Nouvelle.

Love, T. \& Cooper, T. (2003). Designing online information systems for portfolio-based assessment: Design criteria and heuristics. Journal of Information Technology Education, 3 (1), 65-81.

Mialaret, G., (1999). Il sapere pedagogico. Lecce: Pensa Multimedia.

Scurati, C., \& Zanniello G. (Eds.). (1993). La ricerca azione. Naples: Tecnodid.

Susman, G., \& Evered, R. (1978). An assessment of the scientific merits of action research. Administrative Science Quarterly, 23 (4), 582-603.

Vaj, E. (2003). Il portfolio delle competenze individuali. Retrieved December 2, 2004, from http://www.bdp.it/inriforma/pdf/vaj_portfolio.pdf

Varisco, B. M. (2002). Costruttivismo socio culturale. Rome: Carocci.

Winter, R. (1996). Some principles and procedures for the conduct of action research. In Ortrun ZuberSkerritt (Ed.), New directions in action research (pp.13-27), London: Falmer Press.

\section{Biography}

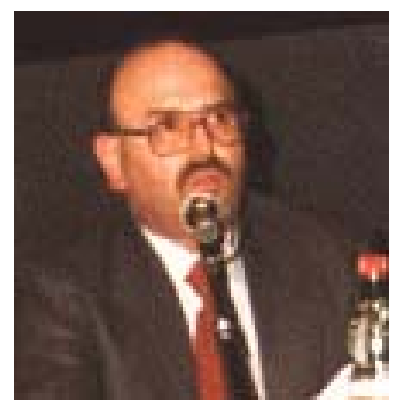

Antonio Cartelli is researcher in Didactics and manages the Centre for ICT and on line teaching in the Faculty of Humanities at the University of Cassino - Italy. Among his interests are: misconceptions, mental schemes, Information Systems for research and teaching, Web Technologies in teaching research and their everyday application for the improvement of teaching and learning. He is also author of many papers concerning the themes he is interested in. 